\title{
Atrial natriuretic peptide and red cell 2,3-diphosphoglycerate in patients with chronic mountain sickness
}

\author{
RI-LI GE, MD, PhD; HE-RU SHAI, MD; M. TAKEOKA, PhD; M. HANAOKA, MD, PhD; T. KOIZUMI, MD, \\ PhD; Y. MATSUZAWA, MD; K. KUBO, MD, PhD; T. KOBAYASHI, MD, PhD \\ From the Qinghai High Altitude Medical Science Institute, Xining, Qinghai, China (Drs Ge and Shai); and First Department of Internal \\ Medicine, Sinshu University School of Medicine, Matsumoto, Japan (Drs Takeoka, Hanaoka, Koizumi, Matsuzawa, Kubo, and Kobayashi). \\ $\mathrm{Dr} \mathrm{Ge}$ is now at the Institute for Exercise and Environmental Medicine, Presbyterian Hospital Dallas, University of Texas Southwestern \\ Medical Center, Dallas, TX, USA.
}

Background.--Individuals with chronic mountain sickness (CMS) show severe hypoxemia, excessive polycythemia, and marked pulmonary hypertension. The pathophysiologic mechanisms of CMS are still not completely understood.

Methods.-We determined plasma atrial natriuretic peptide (ANP), red cell 2,3-diphosphoglycerate (2,3-DPG), hematocrit, hemoglobin, and arterialized ear lobe blood gas values in 13 patients with CMS (9 Hans, 4 Tibetans) and 18 control Han Chinese men of similar age, height, and weight who had been living at $4300 \mathrm{~m}$ on the Tibetan plateau of Qinghai Province, China, for approximately 14 years.

Results.-A significantly higher level of ANP was found in the CMS patients compared to the non-CMS patients $(113.4 \pm 5.5 \mathrm{pg} / \mathrm{mL}$ vs $87.6 \pm 4.7 \mathrm{pg} / \mathrm{mL}, P<.01)$, and the levels of ANP correlated positively with the hemoglobin concentration $(r=0.8282, P<.01)$. The 2,3-DPG levels in the CMS patients were significantly increased compared to the non-CMS subjects $(5.23 \pm 0.16$ $\mathrm{mmol} / \mathrm{L}$ vs $4.40 \pm 0.12 \mathrm{mmol} / \mathrm{L}, P<.01)$, and the $2,3-\mathrm{DPG}$ concentrations in the CMS patients were negatively correlated with their $\mathrm{PaO}_{2}$ values $(r=-0.7898, P<.01)$. The CMS patients had significantly higher $\mathrm{PaCO}_{2}$ levels, lower $\mathrm{pH}$ values, lower $\mathrm{PaO}_{2}$ levels, and greater alveolar-arterial oxygen differences $\left(\mathrm{PAO}_{2}-\mathrm{PaO}_{2}\right)$ compared to the non-CMS subjects.

Conclusions.- These findings suggest that overproduction of ANP and 2,3-DPG at high altitudes may play an important role in the pathophysiology of chronic mountain sickness.

Key words: chronic mountain sickness, hypoxia, polycythemia, gas exchange, pulmonary hypertension

\section{Introduction}

Human beings who live at high altitude usually undergo several types of adaptation that allow them to survive in hypoxic environments. However, a small number of people who are lifelong residents at altitudes above $3000 \mathrm{~m}$ develop various clinical symptoms and signs of chronic mountain sickness (CMS), including headache, dyspnea, sleepiness, cyanosis of lips and face, and physical and mental fatigue. Chronic mountain sickness was first described in 1928 by Carlos Monge ${ }^{1}$ and is a multifactorial

Corresponding author: Keishi Kubo, MD, PhD, First Department of Internal Medicine, Sinshu University School of Medicine, 3-1-1 Asahi, Matsumoto, Japan. and multisystemic syndrome. The most striking features of this syndrome are severe hypoxemia, excessive polycythemia, and pulmonary hypertension. An epidemiological study 2 of CMS in Qinghai Province, China, estimated that the incidence of CMS was $10.1 \%$ at 3714 $\mathrm{m}$ and reported that the Tibetan natives had a substantially lower incidence of CMS than did the immigrant Hans. Studies in Peru by Leon-Velarde et $\mathrm{al}^{3}$ showed that the incidence of CMS in females, particularly in their premenopausal years, is far less than that in males, and that the hemoglobin concentration increases with age. It is known that hypoxia is an etiologic key to the development of CMS, but the pathogenesis of CMS is not fully understood. In the present study, we measured 
Table 1. Anthropometric and hematologic parameters of the subjects*

\begin{tabular}{lrcc}
\hline & \multicolumn{1}{c}{ CMS } & Non-CMS & $P$ \\
\hline No. of subjects & $13(4) \dagger$ & 18 & $\ldots$ \\
Age, y & $36.1 \pm 2.6$ & $38.8 \pm 2.1$ & NS \\
Height, cm & $169.2 \pm 1.9$ & $170.3 \pm 2.0$ & NS \\
Weight, kg & $62.5 \pm 1.8$ & $60.3 \pm 1.5$ & NS \\
Residence, y & $14.4 \pm 1.8$ & $14.5 \pm 2.3$ & NS \\
Hb, g/dL & $22.3 \pm 0.5$ & $17.3 \pm 0.4$ & $<.01$ \\
Hct, \% & $69.0 \pm 0.8$ & $59.6 \pm 1.2$ & $<.01$ \\
Smoking, pack-years & $27.2 \pm 2.6$ & $10.5 \pm 0.9$ & $<.01$ \\
\hline
\end{tabular}

*Values are presented as means \pm SEM. CMS indicates chronic mountain sickness; Hb, hemoglobin; Hct, hematocrit; and NS, not significant.

$\uparrow$ No. of CMS subjects includes 4 Tibetans who were born at 2260 $\mathrm{m}$, but had been living at $4300 \mathrm{~m}$ for about 20 years.

the plasma atrial natriuretic peptide (ANP) and red cell 2,3-diphosphoglycerate (2,3-DPG) levels in 13 patients with CMS and 18 subjects without CMS (non-CMS). We discuss the possible role of these 2 substances in the development of CMS at high altitude.

\section{Materials and Methods}

\section{SUBJECTS}

This study was performed using 13 male patients with CMS (9 Han Chinese and 4 Tibetans) and 18 healthy male control subjects (Han Chinese, non-CMS) at an altitude of $4300 \mathrm{~m}$ (barometric pressure $440 \mathrm{~mm} \mathrm{Hg}$ ) in the Madu area of Qinghai Province. The Han subjects were born at or near sea level and had migrated to Madu $14.5 \pm 2.3$ years earlier (in the non-CMS group) or 14.4 \pm 1.8 years earlier (in the CMS group). The 4 Tibetans with CMS were born at an altitude of $2260 \mathrm{~m}$ in Qinghai and had lived at $4300 \mathrm{~m}$ for the preceding 20 years. The occupations of the subjects were clerical workers, schoolteachers, and road workers. The majority of the subjects in both groups smoked cigarettes, and the average pack-year was $10.5 \pm 0.9$ in the non-CMS group and $27.2 \pm 2.6$ in the CMS group. The general characteristics of the subjects are given in Table 1. All subjects gave informed consent to participate in the study, and the study protocol was approved by the Institutional Committee for Human Research of the High Altitude Medical Science Institute, Qinghai.

\section{DIAGNOSIS}

The diagnosis of CMS was made according to the classification and criteria of CMS reported by the Chinese
Society for High Altitude Medicine, ${ }^{4}$ which include the following items: hemoglobin level $>20 \mathrm{~g} / \mathrm{dL}$, hematocrit $>65 \%$, headache, dizziness, cyanosis of lips and face, tinnitus, physical weakness, mental fatigue, sleep disturbance, anorexia, and breathlessness. The patients had no clear evidence of underlying heart disease or chronic obstructive lung disease based on physical examination, electrocardiograms, pulmonary function tests, and chest radiography.

\section{PULMONARY FUNCTION TEST}

Spirometry was performed in triplicate using a flowbased spirometer with a microcomputer (CHA-1600, Fukuda, Tokyo, Japan), and the highest values were used for the analysis. Vital capacity, percentage of forced expiratory volume in 1 second $\left(\mathrm{FEV}_{1 \%}\right)$, mean forced expiratory flow during half of the forced vital capacity $\left(\mathrm{FEF}_{25 \%-75 \%}\right)$, and maximal voluntary ventilation values were recorded and analyzed. The instrument was calibrated with a 1-L syringe at room temperature and by the daytime barometric pressure.

\section{BLOOD GAS ANALYSIS}

Arterialized blood was obtained from the subject's ear after resting for 20 minutes in a chair. The method for the measurement of blood gases has been described previously. ${ }^{5}$ Briefly, a hot water bag (at $45^{\circ} \mathrm{C}$ ) was placed on the ear to establish arterialization of regional blood, and the ear-prick blood was withdrawn with a $125-\mu \mathrm{L}$ heparinized capillary tube. The $\mathrm{pH}, \mathrm{PaO}_{2}$, and $\mathrm{PaCO}_{2}$ levels were then analyzed immediately using a blood gas analyzer (BME-33; Radiometer, Copenhagen, Denmark). The alveolar-arterial oxygen difference $\left(\mathrm{PAO}_{2}-\mathrm{PaO}_{2}\right)$ was calculated using a simplified form of the alveolar air equation $\left(\mathrm{PA}=\mathrm{PIO}_{2}-\mathrm{PaCO}_{2} / \mathrm{R}\right)$; the respiratory exchange ratio $(\mathrm{R})$ was assumed to be 0.80 .

\section{BLOOD MEASUREMENTS}

Four milliliters of blood was taken from the brachial vein, $2 \mathrm{~mL}$ of which was collected in a chilled tube for the measurement of 2,3-DPG, and the other $2 \mathrm{~mL}$ of which was collected in a chilled tube on ice (sodium EDTA $1.5 \mathrm{~mL}$ ) for the measurement of ANP. The blood was centrifuged at $4^{\circ} \mathrm{C}$, and the plasma samples were stored in liquid nitrogen for transport back to Xining, China, for analysis. Atrial natriuretic peptide was measured with a radioimmunoassay kit (RK-9103, Institute of Northeast Immunoassay, Beijing, China). The level of ANP detected by this radioimmunoassay ranges from 62.5 to $2000 \mathrm{pg} / \mathrm{mL}$, and the interassay-intraassay co- 
Table 2. Spirometry and arterial blood gas parameters

\begin{tabular}{lccc}
\hline & CMS & Non-CMS & $P$ \\
\hline No. of subjects & 13 & 18 & $\ldots$ \\
VC, $\mathrm{L}$ & $4.1 \pm 0.2$ & $4.1 \pm 0.1$ & $\mathrm{NS}$ \\
$\mathrm{FEV}_{1}, \%$ & $88.1 \pm 2.4$ & $89.6 \pm 1.5$ & $\mathrm{NS}$ \\
$\mathrm{FEF}_{25 \%-75 \%}, \mathrm{~L} / \mathrm{s}$ & $2.7 \pm 0.3$ & $3.4 \pm 0.4$ & $<.05$ \\
$\mathrm{MVV}, \mathrm{L} / \mathrm{min}$ & $113.5 \pm 6.4$ & $109.8 \pm 3.9$ & $\mathrm{NS}$ \\
$\mathrm{pH}$ & $7.387 \pm 0.008$ & $7.442 \pm 0.003$ & $<.05$ \\
$\mathrm{PaCO}_{2}, \mathrm{~mm} \mathrm{Hg}$ & $28.5 \pm 0.6$ & $26.0 \pm 0.3$ & $<.05$ \\
$\mathrm{PaO}_{2}, \mathrm{~mm} \mathrm{Hg}$ & $47.3 \pm 1.0$ & $53.1 \pm 0.7$ & $<.01$ \\
$\mathrm{PAO}_{2}-\mathrm{PaO}_{2}, \mathrm{~mm}$ & $6.5 \pm 1.0$ & $3.8 \pm 0.4$ & $<.01$ \\
$\mathrm{Hg}$ & & & \\
$2,3-\mathrm{DPG}, \mathrm{mmol} / \mathrm{L}$ & $5.2 \pm 0.2$ & $4.4 \pm 0.1$ & $<.01$ \\
$\mathrm{ANP}_{\mathrm{N}} \mathrm{pg} / \mathrm{mL}$ & $113.4 \pm 5.5$ & $87.6 \pm 4.7$ & $<.01$ \\
& & & \\
\hline
\end{tabular}

*Values presented as means \pm SEM. CMS indicates chronic mountain sickness; $\mathrm{VC}$, vital capacity; $\mathrm{FEV}_{1}$, percentage of forced expiratory volume in $1 \mathrm{~s} ; \mathrm{FEF}_{25 \%-75 \%}$, mean forced expiratory flow during half of the forced vital capacity; MVV, maximal voluntary volume; $\mathrm{PAO}_{2}-\mathrm{PaO}_{2}$, alveolar-arterial oxygen difference; 2,3-DPG, 2,3-diphosphoglycerate; ANP, atrial natriuretic peptide; and NS, not significant.

efficients of variation for measurement of ANP were $6.8 \%$ and $13 \%$, respectively. The concentration of red cell 2,3-DPG was measured with a calorimetric assay kit (Boehringer-Mannheim, Mannheim, Germany) using a DPG standard for quantification. In addition, the blood samples were analyzed for hemoglobin concentrations using the cyanmethemoglobin method and for hematocrit by microcentrifugation.

\section{STATISTICAL ANALYSIS}

Data are expressed as means \pm SEM. Comparisons between the 2 subject groups were made by the Fisher protected least significant difference test at the 95\% significance level. A Student unpaired $t$ test was also used for comparison between the 2 groups (CMS vs nonCMS). A linear regression analysis was used to assess the relationship between variables. The significance level was set at $P<.05$.

\section{Results}

The anthropometric variables and hematologic data of the CMS and non-CMS subjects are shown in Table 1. The 2 groups were similar in terms of age, height, weight, and period of residence at $4300 \mathrm{~m}$, but the members of the CMS group were heavier smokers and had significantly higher hemoglobin concentrations and hematocrit values than the non-CMS group.

Table 2 shows the results of the pulmonary function

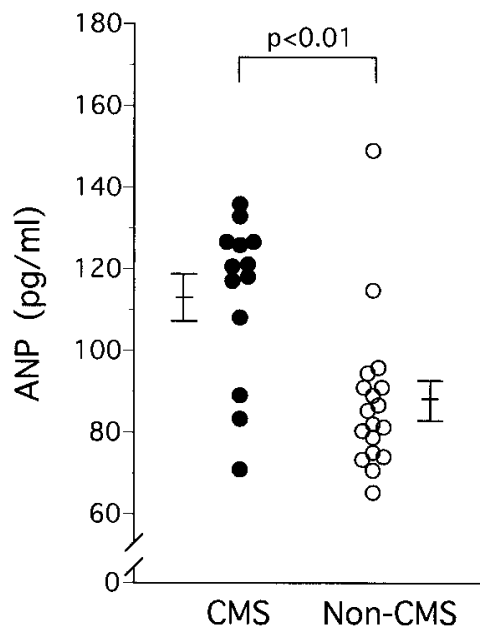

Figure 1. The plasma levels of atrial natriuretic peptide (ANP) in 13 patients with chronic mountain sickness (CMS) and 18 subjects without CMS (non-CMS) living at an altitude of $4300 \mathrm{~m}$. The patients with CMS showed significantly higher ANP levels compared to the non-CMS subjects.

tests and blood gas analyses in the 2 groups. There were no significant differences in vital capacity, $\mathrm{FEV}_{1 \%}$, or maximal voluntary ventilation values between the 2 groups, but significantly decreased $\mathrm{FEF}_{25 \%-75 \%}$ levels were observed in the CMS patients. The CMS patients also showed significantly higher $\mathrm{PaCO}_{2}$ levels, lower $\mathrm{pH}$, lower $\mathrm{PaO}_{2}$ levels, and greater $\mathrm{PAO}_{2}-\mathrm{PaO}_{2}$ values (Table 2). A comparison of the plasma ANP values is illustrated in Figure 1. Significantly higher levels of plasma ANP were found in the patients with CMS compared to the non-CMS subjects $(P<.01)$, and the ANP levels showed a highly positive linear correlation with the hemoglobin concentrations (Figure 2).

The mean 2,3-DPG concentration in the CMS patients was significantly increased compared to the non-CMS subjects (Figure 3 ). In addition, the concentration of red cell 2,3-DPG correlated well with the levels of $\mathrm{PaO}_{2}$ (Figure 4).

\section{Discussion}

The principal finding of the present study was that the CMS patients had significantly higher levels of both ANP and 2,3-DPG compared to the non-CMS subjects, as well as lower $\mathrm{PaO}_{2}$ and greater $\mathrm{PAO}_{2}-\mathrm{PaO}_{2}$ values.

Plasma ANP levels rise significantly after exposure to hypoxia, and higher levels of circulating ANP during hypoxia can protect against the development of pulmonary hypertension. Milledge et $\mathrm{al}^{6}$ and Bärtsch et $\mathrm{al}^{7}$ reported that plasma levels of ANP were significantly elevated in patients with acute mountain sickness and 


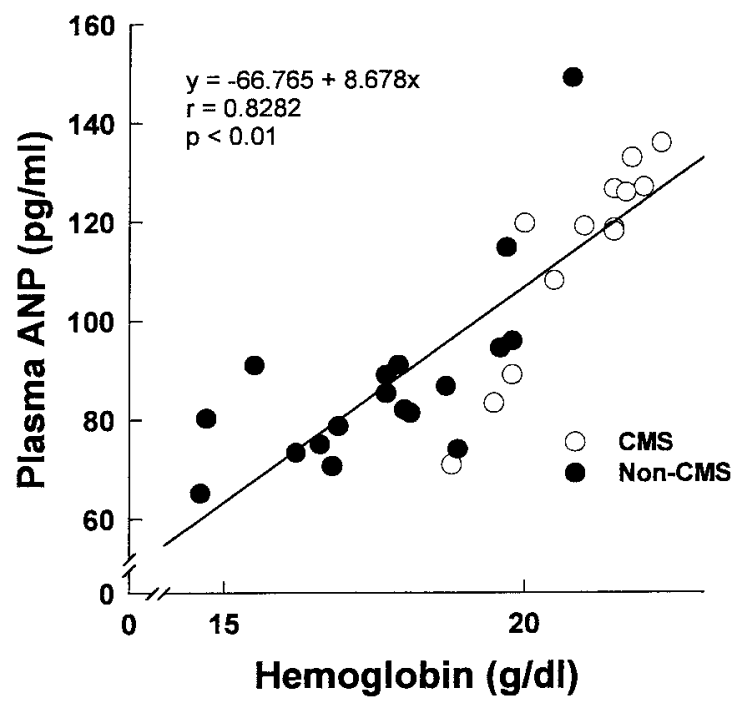

Figure 2. The relationship between plasma atrial natriuretic peptide (ANP) and hemoglobin concentrations in the chronic mountain sickness (CMS) patients and non-CMS subjects. As a whole, there was a significant correlation $(P<.01)$.

high-altitude pulmonary edema, which may be due to an increase in right atrial pressure secondary to hypoxic pulmonary vasoconstriction. However, no data are available regarding plasma ANP levels in patients with CMS at high altitude. We found that plasma ANP levels are higher in patients with CMS than in non-CMS subjects. Increasing ANP levels in CMS patients may be related not only to pulmonary hypertension, but also to changes in plasma ANP clearance. Marked pulmonary hypertension is present in most cases of CMS and decreases rapidly with the administration of oxygen. Penaloza and $\mathrm{Sime}^{8}$ reported from Peru $(4300 \mathrm{~m})$ that mean pulmonary arterial pressure was $47 \mathrm{~mm} \mathrm{Hg}$ in patients with CMS, while it was $23 \mathrm{~mm} \mathrm{Hg}$ in healthy residents at high altitude. Severe pulmonary hypertension was also observed in patients with CMS (mean pulmonary arterial pressure was $38.8 \pm 5.14 \mathrm{~mm} \mathrm{Hg}$ ) compared to nonCMS subjects $(22.3 \pm 4.4 \mathrm{~mm} \mathrm{Hg})$ in Qinghai (3950 m). ${ }^{9}$ It is likely that severe hypoxemia in CMS patients can lead to increased right heart ANP secretion by raising right atrial volume and pressure. Therefore, we speculated that higher levels of plasma ANP in these patients may have resulted from elevations of right heart volume and pressure that is secondary to pulmonary hypertension. In addition, other investigators ${ }^{10,11}$ have reported that the natriuretic peptide receptor-C messenger RNA (ANP clearance receptor) is downregulated in chronically hypoxic rats, suggesting that hypoxia suppresses pulmonary ANP clearance and that clearance of ANP is an important determinant of circulating ANP levels during exposure to chronic hypoxia.

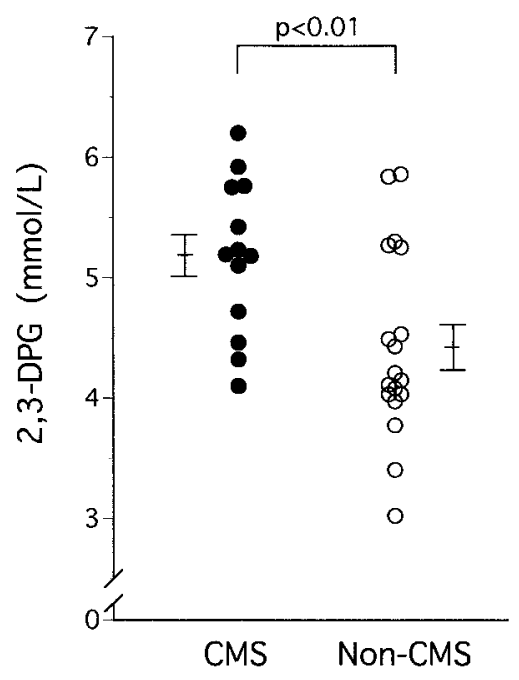

Figure 3. Plasma levels of red cell 2,3-diphosphoglycerate (2,3-DPG) in the patients with chronic mountain sickness (CMS) and in the non-CMS subjects at an altitude of $4300 \mathrm{~m}$. There was a significant increase in the levels of 2,3-DPG in the CMS patients compared to the non-CMS subjects.

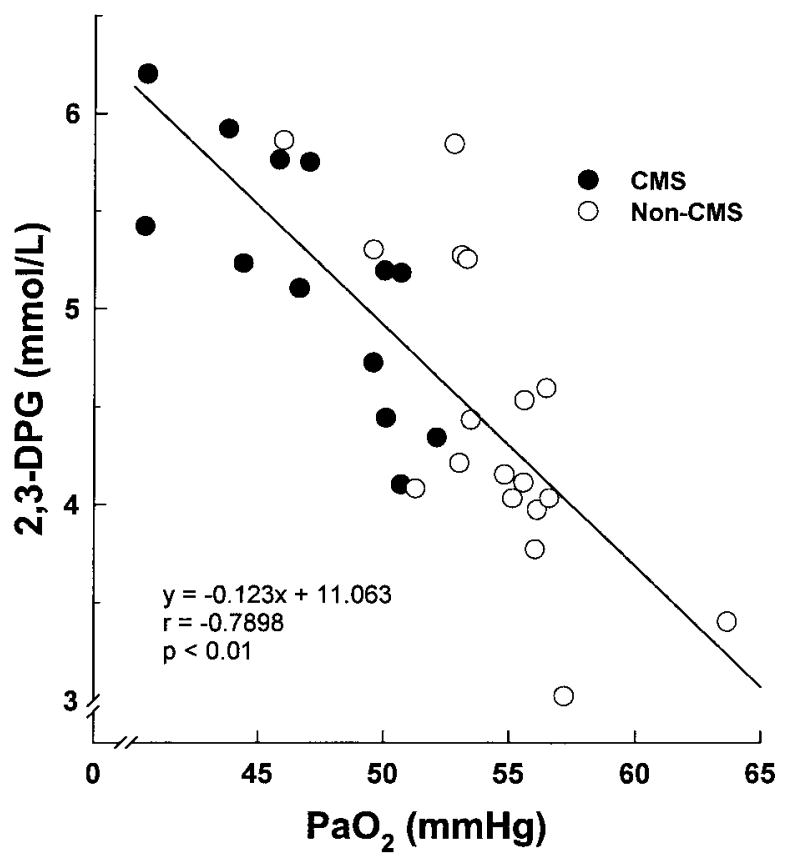

Figure 4. Scatterplot of correlation between the 2,3-diphosphoglycerate (2,3-DPG) and $\mathrm{PaO}_{2}$ values in the patients with chronic mountain sickness (CMS) and the non-CMS subjects. There was a significant negative correlation in both groups $(P$ $<.01)$. 
It is well documented by a previous study that individuals well acclimatized to high altitude exhibit increased levels of red cell 2,3-DPG. ${ }^{12,13}$ Duhm and Gerlach ${ }^{14}$ reported that 2,3-DPG levels increased rapidly in rats when they were exposed to hypoxia for 5 hours to 6 days. Similar results were reported in human studies at different altitudes. ${ }^{13-15}$ Increased 2,3-DPG after acute hypoxic exposure would be related to left shift of the oxygen dissociation curve by hyperventilation, and is an important compensatory mechanism that maintains adequate tissue oxygenation despite reduced oxygen tension. On the other hand, a higher level of 2,3-DPG was observed previously in Peruvian high-altitude natives, which is caused by marked increase in red cell mass. ${ }^{16}$ In our study, higher levels of 2,3-DPG were found in individuals with excessive polycythemia. The level of 2,3-DPG was negatively correlated with $\mathrm{PaO}_{2}$, suggesting that the subjects who had higher levels of 2,3-DPG had significantly lower $\mathrm{PaO}_{2}$. This result is quite similar to the results of other studies, which found that patients with excessive polycythemia at $3440 \mathrm{~m}$ had abnormally high red cell 2,3-DPG values. ${ }^{17}$ The causal relationship between excessive polycythemia and 2,3-DPG level is not yet clear. Studies by Sun et $\mathrm{al}^{18}$ in Tibet and Severinghaus et $\mathrm{al}^{19}$ in Peru indicated that the patients with high-altitude polycythemia had a lower hypoxic ventilatory response and more severe hypoxemia than the non-CMS subjects. Although we did not measure the resting expired volume and hypoxic ventilatory response, a lower $\mathrm{pH}$ and a higher $\mathrm{PaCO}_{2}$ level were observed in the CMS group compared to the non-CMS group. This finding suggests that our CMS patients may have had relative hypoventilation, which in turn led to severe hypoxemia and was the stimulus for excessive production of red cells. It appears that a marked increase in 2,3-DPG in CMS patients may be caused by severe hypoxemia and an increased red cell mass (at least in part). Overproduction of 2,3-DPG can lead to poor oxygenation in the lung due to the oxygen dissociation curve becoming overshifted to the right. Although this condition would facilitate oxygen unloading in the metabolizing tissues, it would be more harmful to oxygen loading in the lung, which may greatly reduce arterial oxygen saturation. Thus, we speculate that 2,3-DPG elevation induced by hypoxia may be a result rather than a cause of the development of polycythemia.

Our patients with CMS had significantly lower $\mathrm{PaO}_{2}$ levels, greater $\mathrm{PAO}_{2}-\mathrm{PaO}_{2}$ values, and higher $\mathrm{PaCO}_{2}$ levels compared to the non-CMS subjects, clearly indicating that the CMS patients had abnormal pulmonary gas exchange. It is not clear, however, whether the polycythemia impairs pulmonary gas exchange. Balgos et $\mathrm{al}^{20}$ found that acute polycythemia had no deleterious effects on pulmonary gas exchange in dogs within the hematocrit range of $36 \%$ to $76 \%$. Kryger et al ${ }^{21}$ noted at $3100 \mathrm{~m}$ that polycythemic patients with lung disease had greater $\mathrm{PAO}_{2}-\mathrm{PaO}_{2}$ values, whereas polycythemic patients with healthy lungs had normal $\mathrm{PAO}_{2}-\mathrm{PaO}_{2}$ values. Our CMS patients had no clear evidence of severe chronic obstructive lung disease by clinical history, chest radiography, and spirometry, but they had significantly greater $\mathrm{PAO}_{2}-\mathrm{PaO}_{2}$ values compared to the nonCMS group, a finding which is quite consistent with another study in Tibet. ${ }^{22}$ The increased $\mathrm{PAO}_{2}-\mathrm{PaO}_{2}$ values in the CMS patients may be caused by regional ventilation-perfusion ratio mismatching, an intrapulmonary shunt caused by severe pulmonary hypertension, microthrombosis in the pulmonary capillaries due to marked increase in red cell mass, or all 3 of these mechanisms. Indeed, it is difficult to rule out other possible causes of impaired pulmonary gas exchange. For example, our subjects who had excessive polycythemia had decreased $\mathrm{FEF}_{25 \%-75 \%}$ values, and these subjects were heavy smokers. Smoking may produce small-airway dysfunction, which may produce further hypoxia and more polycythemia.

In summary, this study demonstrated that patients with CMS, when compared to non-CMS subjects at $4300 \mathrm{~m}$, exhibited significantly higher levels of ANP and 2,3-DPG, and had lower $\mathrm{PaO}_{2}$, greater $\mathrm{PAO}_{2}-\mathrm{PaO}_{2}$, and higher $\mathrm{PaCO}_{2}$ values. Hemoglobin concentrations showed significant positive correlation with ANP levels, and the $\mathrm{PaO}_{2}$ level showed significant negative correlation with 2,3-DPG. These findings suggest that overproduction of ANP and 2,3-DPG at high altitudes may play an important role in the pathophysiology of CMS.

\section{Acknowledgment}

The authors sincerely thank Dr Benjamin D. Levine (Dallas, TX, USA) for critical review of the manuscript.

\section{References}

1. Monge MC. La enfermedad de los Andes: sindromes eritremicos. Ann Fac Med Lima. 1928;11:314.

2. Gou HP, Yang Z, Zhang HM, Su XL, Shu MY. Epidemiological studies of high-altitude polycythemia at $\mathrm{Da} \mathrm{Wu}$ Region (3,700m). Q Med J. 1990;17:56-58.

3. Leon-Velarde F, Ramos MA, Hernandez JA, et al. The role of menopause in the development of chronic mountain sickness. Am J Physiol. 1997;272:R90-R94.

4. Chinese Society for High Altitude Medicine. Recommendation for the definition, classification and diagnostic criteria of chronic mountain sickness. Chin Mountain Med J. 1996;6:2-5.

5. Ge RL, Matsuzawa Y, Takeoka M, Kubo K, Sekiguchi M, 
Kobayashi T. Low diffusion capacity in subjects with acute mountain sickness. Chest. 1997;111:58-64.

6. Milledge JS, Beeley JM, McArthur S, Morice AH. Atrial natriuretic peptide, altitude and acute mountain sickness. Clin Sci. 1989;77:509-514.

7. Bärtsch P, Shaw S, Franciolli M, Gnadinger MP, Weidmann P. Atrial natriuretic peptide in acute mountain sickness. J Appl Physiol. 1988;65:1929-1937.

8. Penaloza D, Sime F. Chronic cor pulmonale due to loss of altitude acclimatization (chronic mountain sickness). Am J Med. 1974;50:728-743.

9. Yang Z, He ZQ, Lui XL. Pulmonary hypertension related to high altitude: an analysis of 83 cases using catheterization. Chin J Cardiol. 1985;13:32-34.

10. Klinger JR, Arnal F, Warburton RR, Ou LC, Hill NC. Downregulation of pulmonary atrial natriuretic peptide receptors in rats exposed to chronic hypoxia. J Appl Physiol. 1994;77:1309-1316.

11. Li H, Oparil S, Meng QC, Elton TS, Chen YF. Selective downregulation of ANP-clearance-receptor gene expression in lung of rats adapted to hypoxia. Am J Physiol. 1995;268:L328-L335.

12. Mairbaurl H, Schobersberger W, Oelz O, Bärtsch P, Eckardt KU, Bauer C. Unchanged in vivo P50 at high altitude despite decreased erythrocyte age and elevated 2,3- diphosphoglycerate. J Appl Physiol. 1990;68:1186-1194.

13. Mairbaurl H, Oelz O, Bärtsch P. Interactions between $\mathrm{Hb}$, $\mathrm{Mg}$, DPG, ATP and CI determine the change in $\mathrm{Hb}-\mathrm{O} 2$ affinity at high altitude. J Appl Physiol. 1993;74:40-48.

14. Duhm J, Gerlach E. On the mechanisms of the hypoxia- induced increase of 2,3-diphosphoglycerate in erythrocytes: studies on rat erythrocytes in vivo and on human erythrocytes in vitro. Pfluegers Arch. 1971;326:254-269.

15. Ge RL, She HR, Chen QH, Gao W, Kubo K, Kobayashi T. Changes of red cell 2,3-DPG in the normal subjects after acute exposure to 4,300m. Chin J Aviat Med. 1994; 5:101-104.

16. Winslow RM, Monge CC, Statham NJ, et al. Variability of oxygen affinity of blood: human subjects native to high altitude. Appl Physiol. 1981;51:1411-1416.

17. Eaton JW, Brewer GJ, Grover RF. Role of red cell 2,3diphosphoglycerate in the adaptation of man to altitude. $J$ Lab Clin Med. 1969;73:603-609.

18. Sun SF, Huang SY, Zhuang ZG, et al. Decreased ventilation and hypoxic ventilatory responsiveness are not reversed by naloxone in Lhasa residents with chronic mountain sickness. Am Rev Respir Dis. 1990;142:1294-1300.

19. Severinghaus JW, Bainton CR, Carcelen A. Respiratory insensitivity to hypoxia in chronically hypoxic man. Respir Physiol. 1966;1:308-334.

20. Balgos AA, Willford DC, West JB. Ventilation-perfusion relationships during normovolemic polycythemia in dogs. J Appl Physiol. 1988;65:1686-1692.

21. Kryger M, McCullough R, Dockel R, Collins D, Weil JV, Grover RF. Excessive polycythemia of high altitude: role of ventilatory drive and lung disease. Am Rev Respir Dis. 1978;118:659-666.

22. Pei SX, Chen XJ, Si Ren ZB, Lui YH, Harrise EM, Anand IS. Chronic mountain sickness in Tibet. Q J Med. 1989; 266:555-574. 